Tohoku J. exp. Med., 1985, 146, 401-403

\title{
Abolition by Nicorandil of Spontaneous Action Potentials of the Small Atrio-Ventricular Node Preparation of the Dog
}

\author{
Toshiniko Iijima and Norio Taira \\ Department of Pharmacology, Tohoku University School of \\ Medicine, Sendai 980
}

\begin{abstract}
Iijima, T. and Taira, N. Abolition by Nicorandil of Spontaneous Action Potentials of the Small Atrio-Ventricular Node Preparation of the Dog. Tohoku J. exp. Med., 1985, 146 (4), 401-403 — Effects of carbachol and nicorandil on spontaneous action potentials were examined in the small atrio-ventricular $(\mathrm{A}-\mathrm{V})$ node preparation of the dog. Carbachol $\left(3 \times 10^{-6} \mathrm{M}\right)$ definitely hyperpolarized the membrane potential and abolished the spontaneous activity. Nicorandil $\left(3 \times 10^{-4}\right.$ M) also abolished the spontaneous activity but the membrane potential became quiescent at $-65 \mathrm{mV}$, which was less negative than the maximum diastolic potential. From these results it appears that nicorandil may increase the potassium conductances but not hyperpolarize the membrane potential because the background potassium conductance is little developed in the nodal cells.

atrio-ventricular node; spontaneous action potential ; carbachol ; nicorandil ; potassium conductance
\end{abstract}

It has been shown that acetylcholine $(\mathrm{ACh})$ binds to muscarinic receptors and opens an ACh activated potassium channel in atrial and nodal cells (Sakmann et al. 1983). Nicorandil, a new coronary vasodilator, also increases potassium conductances of cardiac membranes but without mediation through muscarinic receptors (Yanagisawa and Taira 1980). Both drugs shorten the action potential duration and hyperpolarize the resting membrane potential in the atrial muscle. But hyperpolarization of the resting membrane potential is not obvious with nicorandil in cardiac Purkinje fibers (Yanagisawa and Taira 1981) and the sino-atrial node cells (Satoh and Hashimoto 1984). In the present study effects of carbachol and nicorandil on spontaneous action potentials of the small atrioventricular $(\mathrm{A}-\mathrm{V})$ node preparation were examined to reveal the difference of the two drugs.

\section{Materials and Methods}

Small A-V node preparations from the dog heart were prepared in the same procedure

Received February 25, 1985 ; accepted for publication April 5, 1985. 
described previously (Iijima and Taira 1983). The preparation was superfused with Tyrode solution containing $(\mathrm{mM}): \mathrm{K}^{+}, 2.7 ; \mathrm{Na}^{+}, 149.3 ; \mathrm{Ca}^{2+}, 1.8 ; \mathrm{Mg}^{2+}, 1.0 ; \mathrm{Cl}^{-}, 145.3 ; \mathrm{HCO}_{3}^{-}$, $11.9 ; \mathrm{H}_{2} \mathrm{PO}_{4}{ }^{-}, 0.4$; and dextrose, 5.5, equilibrated with $95 \% \mathrm{O}_{2}$ and $5 \% \mathrm{CO}_{2}$. The $\mathrm{pH}$ of the bathing solution ranged from 7.2 to 7.4 . Tissue bath temperature was maintained at $37 \pm 0.5^{\circ} \mathrm{C}$. After equilibration for at least $60 \mathrm{~min}$, membrane potentials were recorded with glass microelectrodes filled with $3 \mathrm{M} \mathrm{KCl}$ and having a resistance of 15-30 Mohm. Membrane potentials were displayed on an oscilloscope and photographed on $35 \mathrm{~mm}$ film, and also recorded with a pen-recorder.

\section{Results and Discussion}

Carbachol $\left(3 \times 10^{-6} \mathrm{M}\right)$ hyperpolarized the membrane potential and abolished the spontaneous activity (Fig. 1A). The maximum diastolic potential was -70 $\mathrm{mV}$ before the drug application (Fig. 1Aa) and the quiescent membrane potential induced by the drug was $-80 \mathrm{mV}$ (Fig. 1Ab). Nicorandil $\left(3 \times 10^{-4} \mathrm{M}\right)$, on the other hand, also abolished the spontaneous action potential but hyperpolarization of the membrane potential was not obvious (Fig. 1B). The membrane potential

A

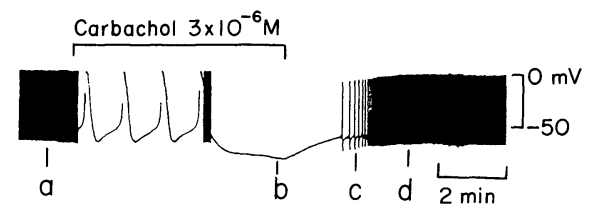

a

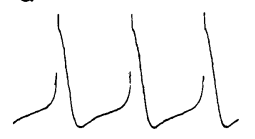

b

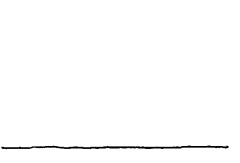

C

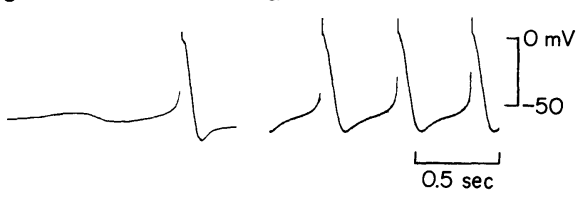

B
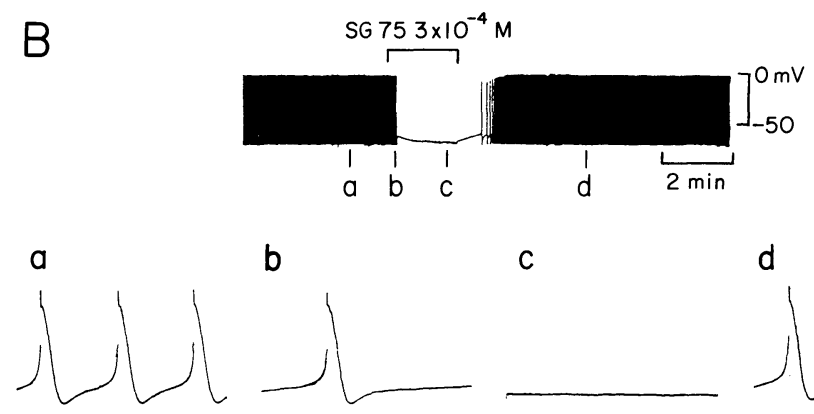

b

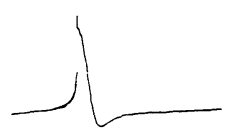

C

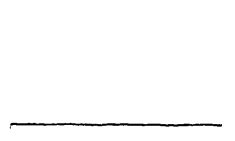

d

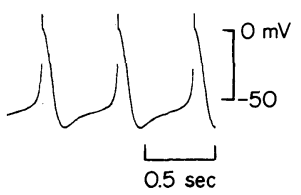

Fig. 1. Effects of carbachol (A) and nicorandil (B) on spontaneous action potentials of the small $\mathrm{A}-\mathrm{V}$ node preparation of the dog. In upper traces of each panel, fast parts of the action potentials were not recorded because of low frequency response of a pen-recorder. 
became stable at $-65 \mathrm{mV}$ (Fig. $1 \mathrm{Bc}$ ), which was less negative than the maximum diastolic potential of $-70 \mathrm{mV}$ (Fig. 1Ba).

It has been reported that in atrial muscle, nicorandil $\left(10^{-6}-10^{-4} \mathrm{M}\right)$ shortened the action potential duration and hyperpolarized the resting membrane potential (Yanagisawa and Taira 1980). In cardiac Purkinje fibers, nicorandil also decreased the action potential duration and produced the reduction of the slope of the slow diastolic depolarization and resulted in the decrease in the spontaneous firing rate. However, nicorandil did not change the maximum diastolic potential (about $-100 \mathrm{mV}$ ), and abolished the action potential at $-80 \mathrm{mV}$ (Yanagisawa and Taira 1984). In the present study, nicorandil slowed the spontaneous firing rate and abolished the spontaneous action potential without hyperpolarizing the membrane potential more than the maximum diastolic potential of the control. These results indicate that carbachol increases the ACh activated potassium conductance in $\mathrm{A}-\mathrm{V}$ nodal cells and hyperpolarize the membrane, and abolishes the spontaneous action potential. Nicorandil, however, may increase both the time-dependent and the time-independent potassium conductances but the latter is little developed in the nodal cells (Kokubun et al. 1982; Noma et al. 1984). Therefore, hyperpolarization may not be induced by nicorandil.

\section{References}

1) Iijima, T. \& Taira, N. (1983) Effects of manganese ions and diltiazem on the spontaneous action potential of the canine atrio-ventricular node cell. J. mol. cell. Cardiol., 15, 863-866.

2) Kokubun, S., Nishimura, M., Noma, A. \& Irisawa, H. (1982) Membrane currents in the rabbit atrioventricular node cell. Pflügers Arch., 393, 15-22.

3) Noma, A., Nakayama, T., Kurachi, Y. \& Irisawa, H. (1984) Resting K conductances in pacemaker and non-pacemaker heart cells of the rabbit. Jap. J. Physiol., 34, $245-254$.

4) Sakmann, B., Noma, A. \& Trautwein, W. (1983) Acetylcholine activation of single muscarinic $\mathrm{K}$ channels in isolated pacemaker cells of the mammalian heart. Nature, 303, 250-253.

5) Satoh, H. \& Hashimoto, K. (1984) Effects of nicorandil on the membrane currents of rabbit sino-atrial node cells. Jap. J. Pharmacol., 34, 411-415.

6) Yanagisawa, T. \& Taira, N. (1980) Effet of 2-nicotinamidethyl nitrate (SG-75) on the membrane potential of left atrial muscle fibers of the dog. Naunyn-Schmiedeberg's Arch. Pharmacol., 312, 69-76.

7) Yanagisawa, T. \& Taira, N. (1981) Effect of 2-nicotinamidethyl nitrate (SG-75) on membrane potentials of canine Purkinje fibers. Jap. J. Pharmacol., 31, 409-417. 